Jurnal Pariwisata Indonesia

Vol 17. No. 12021

Sekolah Tinggi Pariwisata Sahid Surakarta

http://jurnal.stpsahidsurakarta.ac.id/

Jurnal Pariwisata Indonesia

ISSN: 1907-2457 (Print), ISSN: 2581-2688 (Online)

\title{
PENGARUH PENGGUNAAN SARI BUAH STRAWBERRY TERHADAP PENAMPILAN, TEKSTUR, AROMA, WARNA DAN RASA SEBAGAI PENGGANTI AIR MINERAL DALAM PEMBUATAN CHURROS
}

\author{
Angela Devi Widayanti ${ }^{1}$, Ndaru Prasastono ${ }^{2}$, Artin Bayu Mukti ${ }^{3}$ \\ 1,2,3 Fakultas Pariwisata, Universitas Stikubank (UNISBANK) Semarang \\ ${ }^{1}$ Email; angeladevi307@gmail.com \\ 2Email; ndaru_fpar@edu.unisbank.ac.id \\ ${ }^{3}$ Email; bayu fpar@edu.unisbank.ac.id
}

\begin{abstract}
Desserts usually have a sweet and refreshing taste, sometimes some are salty or a combination thereof. Churros are an example of a dessert. Churros are Spanish and Portuguese pastries. Churros are cooked by frying. This research was conducted to determine the effect of using strawberry juice on the appearance, texture, aroma, color and taste as a substitute for mineral water in making Churros. The method used in this research is descriptive type, while the data collection technique is in the form of organoleptic test assessment. Data analysis and discussion used in this study is quantitative data analysis, with a total of 120 respondents. While the conclusion of this research is the effect of using strawberry juice on the appearance, texture, aroma, color and taste as a substitute for mineral water in making Churros.
\end{abstract}

Keywords: Churros, Mineral Water, Strawberry Juice, Organoleptic Test.

Article Information: Submission: 22 Juli 2021, Accepted: 02 Agustus 2021, Published: 03 Agustus 2021 DOI: -

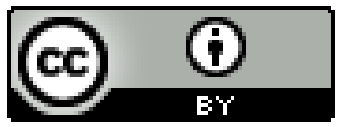

Copyright ( 2021 by the author(s). This article is published by Sekolah Tinggi Pariwisata Sahid Surakarta, Indonesia under the Creative Commons Attribution (CC BY 4.0) license. Anyone may reproduce, distribute, translate, and create derivative works of this article (for both commercial and noncommercial purposes), subject to full attribution to the original publication and author(s). The full terms of this license may be seen at https://creativecommons.org/licenses/by/4.0/ 


\section{PENDAHULUAN}

Pastry atau bisa juga disebut patiseri merupakan salah satu pengetahuan dalam pengolahan dan penyajian makanan, khusus mengolah dan menyajikan berbagai jenis kue. Patiseri berasal dari Bahasa Perancis yaitu "Patisserie" yang artinya kue-kue. Dengan demikian patiseri dapat diartikan sebagai ilmu pengetahuan yang mempelajari tentang seluk beluk kue, baik kue kontinetal, oriental maupun kue tradisonal mulai dari persiapan, pengolahan sampai pada penyajian.

Patiseri terbagi dua, yaitu kue-kue oriental dan kue-kue kontinental. Kue-kue Indonesia termasuk jenis kue oriental, sedangkan yang termasuk kue kontinetal adalah yeast product, breads, dessert, cake and icing, cookies, cream, dan pudding.

Churros merupakan salah satu contoh makanan penutup (dessert). Churros adalah kue kering khas Spanyol dan Portugal. Churros sepintas mirip dengan sus kering berbentuk panjang, namun churros memiliki perbedaan dengan sus kering. Apabila sus dimasak dengan cara dipanggang, lain halnya dengan churros. Churros dimasak dengan cara digoreng.

Churros biasanya memiliki tekstur yang renyah, aroma yang harum dan rasa yang gurih berwarna kuning kecoklatan karena proses penggorengan. Churros bisa disajikan dengan berbagai macam cocolan seperti saus coklat, karamel, atau gula bubuk.

Berdasarkan penjelasan tersebut, peneliti tertarik untuk berinovasi membuat Churros dengan menggunakan sari buah strawberry dan pengaruhnya terhadap penampilan, tektur, aroma, warna dan rasa sebagai pengganti air mineral.

Berkaitan dengan penelitian ini, maka batasan masalahnya yang akan dibahas hanya pada pengaruh penggunaan sari buah strawberry terhadap penampilan, tektur, aroma, warna dan rasa sebagai pengganti air mineral dalam pembuatan Churros dengan panjang ukuran Churros adalah $7 \mathrm{~cm}$.

Sedangkan perumusan masalah dalam penelitian ini adalah bagaimana pengaruh penggunaan sari buah strawberry terhadap penampilan, tektur, aroma, warna dan rasa sebagai pengganti air mineral dalam pembuatan Churros.

\section{TINJAUAN PUSTAKA}

Pastry merupakan salah satu pengetahuan dalam pengolahan dan penyajian makanan terutama kue, baik itu kue continental maupun kue oriental. Nama pastry sendiri sebenarnya berasal dari bahasa Perancis yaitu patisserie yang berarti kue.

Menurut Sudewi dan Patriasih (2005) Pastry ialah adonan yang berlapis-lapis dengan mentega atau lemak agar memperoleh hasil berlapisan atau berlembaran. Pastry adalah jenis makanan dari beberapa kombinasi bahan yang pada umumnya berasa manis, biasanya mengandung lemak dan melalui tahap pembakaran. Jenis makanan ini biasanya disajikan sebagai hidangan penutup.

Menurut Subagjo (2007:87), Pastry adalah bagian dari food product atau kitchen yang ada di dalam lingkup food and beverage departement yang mempunyai tugas dalam pembuatan dessert atau makanan penutup, snack atau makanan pengirim minuman, seperti kue dan roti.

Sedangkan menurut Bartono (2005:164) mengatakan bahwa pastry merupakan bagian dari dapur yang memproduksi khususnya berbagai jenis roti, cake, dan dessert.

Berdasarkan definisi di atas dapat dijelaskan pengertian pastry yaitu adonan yang berlapis-lapis dengan mentega atau lemak agar memperoleh hasil berlapisan atau berlembaran, dimana pastry juga merupakan bagian dapur yang mempunyai tugas dalam pembuatan dessert, snack, cake, dan roti.

Assauri (2008:241), bahan baku adalah semua bahan baku termasuk semua bahan yang digunakan dalam perusahaan manufaktur kecuali untuk bahan yang secara fisik dikombinasikan dengan produk yang diproduksi oleh perusahaan manufaktur ini.

Mulyadi (2005:275) menyatakan bahan baku adalah bahan yang membentuk seluruh bagian. Sedangkan menurut Prawirosentono (2001:61) bahan baku adalah bahan utama dari suatu produk atau barang.

Pendapat Kholmi (2003:29) bahan baku adalah bahan yang membentuk sebagian besar produk jadi, bahan baku yang diolah dalam perusahaan manufaktur dapat diperoleh dari pembelian lokal, impor atau keperluan pengolahan sendiri.

Berdasarkan pendapat tersebut dapat didefinisikan bahwa bahan baku adalah semua bahan yang digunakan untuk membentuk sebagian 
atau seluruh dari suatu produk jadi yang dapat diolah dan diperoleh dengan cara pembelian untuk keperluan sendiri.

Churros adalah kue yang panjang dan lembut dibuat dari campuran tepung dan air lalu digoreng dalam minyak panas hingga berwarna cokelat keemasan. Hidangan ini sangat populer dan biasanya disebut sebagai donat Spanyol dan sudah mencapai status cultural simbol pangan nasional negara Spanyol. Churros juga dikenal dengan beberapa alternatif seperti porras, papitas, dan calentitos.

(https://www.encyclopedia.com/education/ dictionaries-thesauruses-pictures-and-pressreleases/churros)

Churros mempunyai dua sisi sejarah yang berlawanan, yakni sisi sejarah pertama menyatakan bahwa churros dipopulerkan dari seorang penggembala asal Spanyol yang tinggal didaerah gunung kemudian jauh dan terisolasi dari segala macam produk bahan baku yang berkualitas sehingga pada akhirnya para penggembala di daerah tersebut datang dan membawa sebuah kue yang terbuat dari campuran tepung terigu dengan air kemudian dibentuk dengan bentuk memanjang seperti permen yang kemudian dipersiapkan diatas wajan dengan api terbuka. Sisi sejarah lainnya menjelaskan bahwa churros terinspirasi dari You Tiao yakni sebuah panganan berbentuk panjang yang digoreng dan dibuat oleh masyarakat hina di bagian utara.

Bahan churros biasanya menggunakan air mineral untuk memasaknya bersama margarin. Pada pembuatan churros yang inovatif, peneliti mencoba untuk mengganti air mineral dengan sari buah strawberry. Selain hanya air mineral yang digunakan, warna dalam buah strawberry sendiri dapat berpengaruh dengan warna churros.

Menurut Cahya bentuk-bentuk churros yang ada yaitu bulat, panjang, love, puff pastry. Adapun varian rasa yang lain dalam churros yaitu seperti red velvet, oreo, dan matcha.

(https://www.idntimes.com/food/diningguide/putriana-cahya/11-ide-unik-olahan-churroyang-kreatif-bikin-gak-bisa-setop-makan/11).

Menurut Wikipedia, air mineral adalah air yang mengandung mineral atau bahan-bahan larut lain yang mengubah rasa atau memberi nilai-nilai terapi. Banyak kandungan garam, sulfur, dan gasgas yang larut dalam air ini. Air mineral biasanya masih memiliki buih. Air mineral bersumber dari mata air yang berada di alam.
(https://id.wikipedia.org/wiki/Airmineral\#: :text =Air\%20mineral\%20adalah\%20air\%20yang,air \%20yang\%20berada\%20di\%20alam.

Menurut Standart Nomor Indonesia (SNI) 01-3553-2006 Air mineral adalah air minum dalam kemasan yang mengandung mineral dalam jumlah tertentu tanpa menambahkan mineral.

Sedangkan menurut Faridah (2008) air merupakan komponen penting dalam bahan makanan, karena air dapat mempengaruhi penampilan, tekstur, serta cita rasa makanan. Bahkan dalam bahan makanan yang kering sekalipun, seperti buah kering, tepung serta bijibijian, terkandung air dalam jumlah tertentu.

Dari penjelasan tersebut, maka air mineral merupakan air minum dalam kemasan yang mengandung mineral dan bahan-bahan larut lainnya yang merupakan komponen penting dalam bahan makanan, karena mempengaruhi penampilan, tekstur, serta cita rasa makanan.

Buah dianggap sebagai produk tanaman yang berdaging dan manis, dalam arti botani buah didefinisikan sebagai ovarium matang dari tanaman berbunga dan mengandung biji. Buahbuahan merupakan bahan makanan yang banyak mengandung vitamin dan mineral yang diperlukan dalam tubuh manusia. Selain itu, buah-buahan juga kaya akan serat dan enzim yang bermanfaat bagi sistem pencernaan, serta megandung gula yang dibutuhkan sebagai salah satu sumber energi. Buah bisa dimakan dalam keadaan segar atau dapat dikonsumsi buah tersebut musiman ataupun tersedia sepanjang musim (Adrian, 2011).

Buah strawberry mempunyai rasa khas yang manis dan menyegarkan. Selain itu buah strawberry mempunyai kandungan (gizi) yang tinggi dan komposisi gizi cukup lengkap. Buah strawberry dapat dikonsumsi dalam keadaan segar maupun buah yang telah diolah menjadi berbagai macam makanan dan minuman. Aneka macam produk olahan strawberry yaitu selai atau jam, jelly, sirup, ice cream, dodol, strawberry pada kue, juice, dan lain sebagainya.

Buah strawberry memiliki aroma yang khas, warna merah cerah yang kaya akan pigmen antosianin yang mengandung antiogsidan tinggi dan juga senyawa lain seperti serat, vitamin C, potasain dan asam allagic. Karena kandungan antiogsidannya yang tinggi itulah strawberry mempunyai khasiat yang sangat banyak. Strawberry juga banyak dikonsumsi dalam jumlah 
besar baik dimakan langsung atau dalam makanan olahan.

Satalkar (2009), prinsip pembuatan sari buah pada dasarnya adalah pemisahan senyawa yang larut dengan air yang terkandung dalam buah dengan senyawa yang tidak larut air. Sari buah atau fruit juice adalah cairan yang terdapat secara alami dalam buah-buahan yang merupakan hasil pengepresan, penghancuran atau ekstraksi buah segar yang telah masak melalui proses penyaringan.

Organoleptik merupakan suatu metode yang digunakan untuk menguji mutu suatu bahan atau produk menggunakan panca indera manusia. Pengujian organoleptik digunakan terhadap pengujian bahan makanan berdasarkan kesukaan dan kemauan terhadap suatu produk. Uji organoleptik atau uji indera atau uji sensori merupakan cara pengujian tradisional, merupakan cara pengujian dengan menggunakan indera manusia sebagai alat utama untuk pengukuran daya penerimaan terhadap produk. Uji organoleptik sama dengan kualitas makanan.

Menurut Waysima dan Adawiyah (2010), uji organoleptik atau evaluasi sensoris merupakan suatu pengukuran ilmiah dalam mengukur dan menganalisa karakteristik suatu bahan pangan yang diterima oleh indera penglihatan, pencicipan, penciuman, perabaan, dan menginterpretasikan reaksi dari akibat proses penginderaan yang dilakukan oleh manusia yang juga bisa disebut responden sebagai alat ukur.

Uji organoleptik adalah menguji suatu mutu makanan menggunakan indera manusia, supaya produk tersebut dapat diterima oleh pelanggan. Mulai dari penglihatan, pencicipan, penciuman dan perabaan.

Kualitas makanan menurut Peri (2006) dalam Winarjo dan Japarinto (2017:1) menyatakan bahwa memberikan kualitas makanan yang sesuai dengan harapan pelanggan dapat memberikan pengaruh yang positif untuk hubungan antara perusahaan dan pelanggan. Penilaian pelanggan dimulai dari saat pelanggan mencicipi makanan tersebut. Kualitas makanan merupakan kesesuaian makanan yang dikonsumsi oleh pelanggan.

Menurut Potter dan Hotchkiss (2012) food quality atau kualitas makanan adalah karakteristik kualitas dari makanan yang dapat diterima oleh konsumen, seperti ukuran, bentuk, warna, konsistensi, tekstur, dan rasa. Makanan lezat dan segar memainkan peran penting dalam upaya untuk melampaui pesaing. Dengan demikian, kualitas makanan adalah salah satu cara terbaik untuk memaksimalkan keberhasilan dalam bisnis restoran.

Berdasarkan definisi tersebut diatas dapat dijelaskan bahwa kualitas makanan yaitu kesesuaian makanan yang diterima dan dikonsumsi oleh pelanggan dari karakteristik makanan, seperti ukuran, bentuk, warna, konsistensi, tekstur, dan rasa. Makanan lezat dan segar memainkan peran penting dalam upaya untuk melampaui pesaing, itu merupakan cara terbaik untuk memaksimalkan keberhasilan dalam bisnis restoran.

West, Wood dan Harger (2006:39); Gaman dan Sherrington (1996:132); serta Jones (2000:109-110) menyatakan bahwa secara garis besar dimensi food quality terdiri dari:

1. Warna, warna dari bahan-bahan makanan harus dikombinasikan sedemikian rupa supaya tidak terlihat pucat atau warnanya tidak serasi. Kombinasi warna sangat membantu dalam selera makan konsumen.

2. Penampilan, makanan harus baik dilihat saat berada dipiring, dimana hal tersebut adalah suatu faktor yang penting. Kesegaran dan kebersihan dari makanan yang disajikan adalah contoh penting yang akan mempengaruhi penampilan makanan baik atau tidak untuk dinikmati.

3. Porsi, penyajian makanan biasanya sudah ditentukan porsi standarnya yang disebut standar portion size. Standart portion size disefinisikan sebagai kuantitas item yang harus disajikan setiap kali item tersebut dipesan.

4. Bentuk, bentuk makanan memainkan peranan penting dalam daya tarik mata. Bentuk makanan yang menarik bisa diperoleh lewat cara pemotongan bahan makanan yang bervariasi.

5. Temperatur, konsumen menyukai variasi temperatur yang didapatkan dari makanan satu dengan lainnya, karena temperatur juga bisa mempengaruhi rasa.

6. Tekstur, ada banyak macam tekstur makana yaitu halus atau tidak, keras atau lembut, cair atau padat, empuk atau tidak.

7. Aroma adalah reaksi dari makanan yang akan mempengaruhi konsumen sebelum konsumen menikmati makanan, konsumen dapat mencium makanan tersebut. 
8. Tingkat Kematangan, makanan akan mempengaruhi tekstur dari makanan. Misalknya, wortel yang direbus di dalam air mendidih yang lama akan membuat wortel menjadi lunak. Makanan tertentu seperti steak setiap orang memiliki selera masing-masing untuk tingkat kematangan.

9. Rasa, titik perasa dari lidah adalah kemampuan mendeteksi dasar yaitu manis, asam, asin, pahit. Makanan tertentu seringkali menggabungkan empat rasa ini di dalam makanan menjadi satu rasa yang unik dan menarik untuk dinikmati

\section{METODE PENELITIAN}

Metode yang digunakan dalam penelitian ini adalah metode penelitian deskriptif. Deskriptif yaitu, penelitian yang dilakukan untuk mengetahui nilai variabel mandiri, baik satu variabel atau lebih (independen) tanpa membuat perbandingan, atau menghubungkan dengan variabel lain.

Peneliti menggunakan tipe deskriptif untuk memberikan gambaran dan penjelasan mengenai penggunaan sari buah strawberry terhadap penampilan, tekstur, aroma, warna dan rasa sebagai pengganti air mineral dalam pembuatan churros.

\section{Spesifikasi Penelitian}

Menurut Sugiyono (2013:13) penelitian kuantitatif adalah metode penelitian yang berlandaskan terhadap filsafat positivisme. Metode ini digunakan dalam meneliti terhadap sampel dan populasi penelitian, teknik pengambilan sampel umumnya dilakukan dengan cara acak. Penelitian yang digunakan penelitian kuantitatif, mengenai penggunaan sari buah strawberry terhadap penampilan, tekstur, aroma, warna dan rasa sebagai pengganti air mineral dalam pembuatan churros.

\section{Jenis Data}

Jenis data yang digunakan dalam penelitian ini terdiri dari 2 (dua) jenis data yaitu data primer dan data sekunder. Data primer yaitu data yang diperoleh secara langsung dari sumbernya, diamati dan dicatat oleh peneliti. Data penelitian diambil dari hasil kuesioner yang telah diisi oleh responden. Sedangkan data sekunder adalah data yang didapat dari referensi, brosur, majalah, dan dokumen-dokumen lain yang berhubungan dengan penelitian ini yaitu penggunaan sari buah strawberry terhadap penampilan, tekstur, aroma, warna dan rasa sebagai pengganti air mineral dalam pembuatan churros.

\section{Metode Pengumpulan Data}

Sugiyono (2012:7) metode kuantitatif dinamakan metode tradisional, karena metode ini sudah cukup lama digunakan sehingga sudah mentradisi sebagai metode untuk penelitian. Adapun metode pengumpulan datanya meliputi: Responden adalah orang-orang yang merespon atau menjawab pertayaan penelitian baik pertanyaan tertulis maupun lisan (Arikunto, 2003:10). Peneliti membutuhkan responden untuk dapat menjawab pertanyaan mengenai penggunaan sari buah strawberry terhadap penampilan, tekstur, aroma, warna dan rasa sebagai pengganti air mineral dalam pembuatan churros. Kuesioner adalah metode pengumpulan data yang dilakukan dengan cara memberi seperangkat pertanyaan atau pernyataan tertulis kepada responden untuk dijawab (Sugiyono (2012:142). Untuk memperoleh data dalam mendukung penelitian ini peneliti menyebarkan kuesioner kepada 120 responden mengenai penggunaan sari buah strawberry terhadap penampilan, tekstur, aroma, warna dan rasa sebagai pengganti air mineral dalam pembuatan churros. Studi Pustaka, metode pengumpulan data dengan mengadakan studi terhadap bukubuku, literatur, catatan dan laporan yang ada hubungannya dengan masalah yang dipecahkan.

\section{Metode Analisis Data}

Metode analisis data yang diterapkan oleh penulis adalah analisis data kuantitatif, Menurut Moleong (2011) analisis data adalah proses mengorganisasikan dan mengurutkan data kedalam pola, kategori, dan satuan uraian dasar sehingga dapat ditmukan tema dan tempat dirumuskan hipotesis kerja seperti yang disarankan oleh data.

Pada metode analisis data ini menggunakan uji organoleptik yang berdasarkan pada proses penginderaan.

Menurut Waysima dan Adawiyah (2010), uji organoleptik atau evaluasi sensoris merupakan suatu pengukuran ilmiah dalam mengukur dan menganalisa karakteristik suatu bahan pangan yang diterima oleh indera penglihatan, pencicipan, penciuman, perabaan, dan menginterpretasikan 
reaksi dari akibat proses penginderaan yang dilakukan oleh manusia yang juga bisa disebut panelis sebagai alat ukur.

\section{Metode Penyajian Data}

Penyajian data yang digunakan adalah deskriptif kuantitatif. Penyajian data deskriptif kuantitatif adalah penyajian hasil penelitian dengan angka-angka statistik. Adapun metode penyajian datanya meliputi: penelitian eksperimen merupakan penelitian untuk menguji suatu ide, praktek atau prosedur untuk menentukan apak mempengaruhi hasil atau variabel dependen (Creswell, 2012:295).

Sedangkan menurut Sukardi (2011:179) penelitian eksperimen pada prinsipnya dapat didefinisikan sebagai metode sistematis guna membangun hubungan yang mengandung fenomena sebab akibat (casual-effect relationship). Dalam penelitian ini, peneliti melakukan eksperimen penggunaan sari buah strawberry terhadap penampilan, tekstur, aroma, warna dan rasa sebagai pengganti air mineral dalam pembuatan churros.

\section{HASIL DAN PEMBAHASAN Deskripsi Responden}

Deskripsi responden merupakan gambaran umum mengenai jati diri responden yang telah membantu peneliti dalam melakukan penelitian dalam bentuk menjawab pertanyaan-pertanyaan yang peneliti berikan melalui kuesioner. Adapun responden dalam hal ini adalah orang-orang yang telah berkenan mencoba sampel produk yang peneliti buat yaitu penggunaan sari buah strawberry terhadap penampilan, tekstur, aroma, warna dan rasa sebagai pengganti air mineral dalam pembuatan churros.

\section{Berdasarkan Jenis Kelamin}

Hasil olah data kuesioner tentang identitas responden yang telah mengisi dan menjawab pertanyaan pada kuesioner tersebut, maka dapat diketahui bahwa identitas responden berdasarkan jenis kelamin adalah sebagai berikut:

Tabel 1. Berdasarkan Jenis Kelamin

\begin{tabular}{|c|l|c|c|}
\hline No & Jenis Kelamin & Jumlah & Persen \\
\hline 1 & Laki-laki & 54 & $45 \%$ \\
\hline 2 & Perempuan & 66 & $55 \%$ \\
\hline & Jumlah & 120 & $100 \%$ \\
\hline
\end{tabular}

Sumber: Data kuesioner

Berdasarkan tabel 1 diatas dapat dilihat bahwa identitas responden berdasarkan jenis kelamin adalah sebanyak 54 responden atau $45 \%$ adalah laki-laki, dan sebanyak 66 responden atau 55\% adalah perempuan. Hal ini menunjukkan bahwa sebagian besar responden adalah perempuan.

\section{Berdasarkan Pendidikan Terakhir}

Hasil olah data kuesioner tentang identitas responden yang telah mengisi dan menjawab pertanyaan pada kuesioner tersebut, maka dapat diketahui bahwa identitas responden berdasarkan pendidikan terakhir adalah sebagai berikut:

Tabel 2. Berdasarkan Pendidikan Terakhir

\begin{tabular}{|c|l|c|c|}
\hline No & $\begin{array}{c}\text { Pendidikan } \\
\text { Terakhir }\end{array}$ & Jumlah & Persen \\
\hline 1 & SMA/SMK & 24 & $20 \%$ \\
\hline 2 & Diploma & 46 & $38,3 \%$ \\
\hline 3 & Sarjana & 36 & $30 \%$ \\
\hline 4 & Pascasarjana & 14 & $11,7 \%$ \\
\hline & Jumlah & 120 & $100 \%$ \\
\hline
\end{tabular}

Sumber: Data kuesioner

Berdasarkan tabel 2 dapat dilihat bahwa identitas responden berdasarkan pendidikan terakhir adalah sebanyak 24 responden atau $20 \%$ adalah SMA/SMK, sebanyak 46 responden atau 38,3\% adalah diploma, sebanyak 36 responden atau 30\% adalah sarjana, dan sebanyak 14 responden atau $11,7 \%$ adalah pascasarjana.

\section{Berdasarkan Usia}

Hasil olah data kuesioner tentang identitas responden yang telah mengisi dan menjawab pertanyaan pada kuesioner tersebut, maka dapat diketahui bahwa identitas responden berdasarkan usia adalah sebagai berikut:

Tabel 3. Berdasarkan Usia

\begin{tabular}{|c|c|c|c|}
\hline No & Usia & Jumlah & Persen \\
\hline 1 & $21-30$ Tahun & 33 & $27,5 \%$ \\
\hline
\end{tabular}




\begin{tabular}{|c|l|c|c|}
\hline 2 & $31-40$ Tahun & 45 & $37,5 \%$ \\
\hline 3 & $41-50$ Tahun & 26 & $21,7 \%$ \\
\hline 4 & $\begin{array}{l}51 \text { Tahun ke } \\
\text { atas }\end{array}$ & 16 & $13,3 \%$ \\
\hline & Jumlah & 120 & $100 \%$ \\
\hline
\end{tabular}

Sumber: Data kuesioner

Berdasarkan tabel 3 dapat dilihat bahwa identitas responden berdasarkan usia adalah sebanyak 33 responden atau $27,5 \%$ berusia 21-30 tahun, sebanyak 45 responden atau $37,5 \%$ berusia $31-40$ tahun, sebanyak 26 responden atau $21,7 \%$ berusia $41-50$ tahun, sebanyak 16 atau $13,3 \%$ berusia 51 tahun keatas.

\section{Proses Pembuatan Churros}

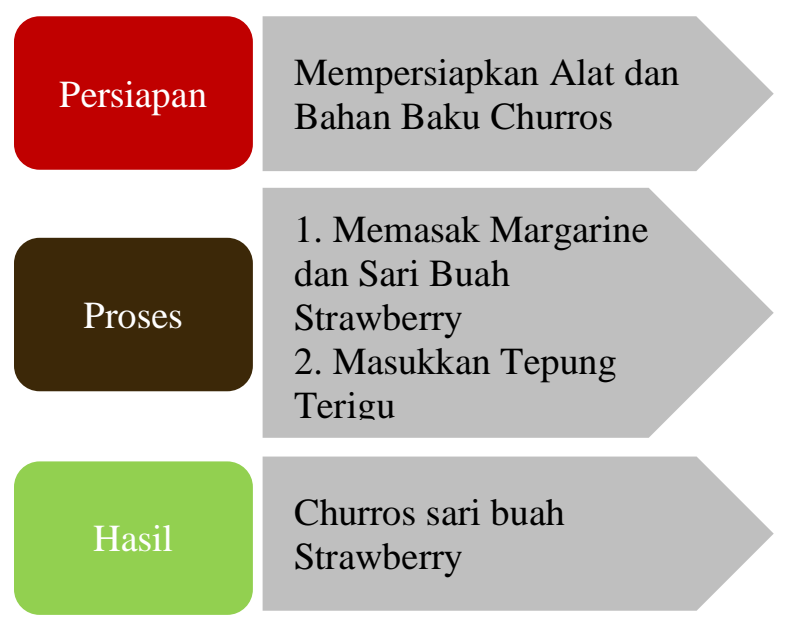

\section{Bagan 1. Proses Pembuatan Churros}

Bahan baku yang digunakan dalam pembuatan churros sari buah strawberry seperti terlihat pada tabel 4 berikut ini:

Tabel 4 Bahan Churros Sari Buah Strawberry

\begin{tabular}{|c|l|l|}
\hline No. & \multicolumn{1}{|c|}{ Bahan } & \multicolumn{1}{|c|}{ Jumlah } \\
\hline 1. & Sari buah strawberry & $500 \mathrm{ml}$ \\
\hline 2. & Margarin & 75 gram \\
\hline 3. & Tepung Terigu & 240 gram \\
\hline 4. & Telur & 4 butir \\
\hline 5. & Minyak & $1 \mathrm{lt}$ \\
\hline
\end{tabular}

\section{Sumber: Resep Churros}

Proses pembutan churros sari buah strawberry yang pertama yaitu haluskan buah strawberry, ambil sarinya dan masak dengam margarin hingga mendidih lalu masukkan tepung terigu aduk cepat di atas api kecil. Diamkan sampai adonan suam-suam kuku, lalu masukkan telur satu persatu aduk hingga tercampur rata. Masukkan adonan kedalam plastik segitiga yang sudah di beri spuit. Panaskan minyak untuk menggoreng, cetak adonan langsung ke dalam minyak panas, gunakan api sedang agar churros tidak gosong. Masak hingga matang, angkat lalu tiriskan. Untuk resep tersebut mengasilkan 120 pcs ukuran $7 \mathrm{~cm}$.

\section{Penilaian Responden terhadap pembuatan Churros dengan Sari Buah Strawberry.}

Berdasarkan hasil penilaian responden terhadap penampilan, tekstur, aroma, warna, dan rasa pada pembuatan churros dengan sari bauh strawberry, maka diperoleh hasil sebagaimana tersaji pada tabel-tabel berikut ini.

1. Penampilan adalah indikator penilaian terhadap churros sari buah strawberry yang menggunakan indera penglihatan dalam hal ini adalah mata. Adapun penilaian responden terhadap penampilan churros sebagaimana terlihat pada tabel dibawah ini:

Tabel 5. Penampilan Churros Sari Buah Strawberry

\begin{tabular}{|c|l|c|c|}
\hline No & Kriteria Penilaian & Jumlah & Persen \\
\hline 1 & Sangat Tidak Baik & 0 & $0 \%$ \\
\hline 2 & Tidak Baik & 0 & $0 \%$ \\
\hline 3 & Cukup Baik & 41 & $34 \%$ \\
\hline 4 & Baik & 65 & $54 \%$ \\
\hline 5 & Sangat Baik & 14 & $12 \%$ \\
\hline & Total & 120 & $100 \%$ \\
\hline
\end{tabular}

Sumber: Data Kuesioner yang diolah.

Berdasarkan tabel 5 diatas maka hasil penilaian responden terhadap penampilan churros sari buah strawberry sebanyak 41 responden menyatakan cukup baik, sebanyak 65 responden menyatakan baik, dan sebanyak 14 responden menyatakan sangat enak.

2. Tekstur merupakan indikator penilaian terhadap churros sari buah strawberry yang menggunakan indera peraba dalam hal ini adalah tangan atau kulit. Adapun penilaian responden terhadap tekstur churros dengan sari buah strawberry, sebagaimana terlihat pada tabel 6 berikut ini. 
Tabel 6. Tekstur Churros

Sari Buah Strawberry

\begin{tabular}{|c|l|c|c|}
\hline No & Kriteria Penilaian & Jumlah & Persen \\
\hline 1 & $\begin{array}{l}\text { Sangat Tidak } \\
\text { Lembut }\end{array}$ & 0 & $0 \%$ \\
\hline 2 & Tidak Lembut & 0 & $0 \%$ \\
\hline 3 & Cukup Lembut & 49 & $41 \%$ \\
\hline 4 & Lembut & 65 & $54 \%$ \\
\hline 5 & Sangat Lembut & 6 & $5 \%$ \\
\hline & Total & 120 & $100 \%$ \\
\hline
\end{tabular}

Sumber: Data Kuesioner yang diolah

Berdasarkan tabel 6, maka hasil penilaian responden terhadap tekstur churros sari buah strawberry sebanyak 49 responden menyatakan cukup lembut, sedangkan 65 responden menyatakan lembut, dan sebanyak 6 responden menyatakan sangat lembut.

3. Aroma adalah indikator penilaian terhadap churros sari buah strawberry yang menggunakan indera penciuman dalam hal ini adalah hidung. Adapun penilaian responden terhadap aroma churros dengan sari buah strawberry, sebagaimana terlihat pada tabel dibawah ini.

Tabel 7. Aroma Churros

Sari Buah Strawberry

\begin{tabular}{|c|l|c|c|}
\hline No & Kriteria Penilaian & Jumlah & Persen \\
\hline 1 & $\begin{array}{l}\text { Sangat Tidak } \\
\text { Harum }\end{array}$ & 0 & $0 \%$ \\
\hline 2 & Tidak Harum & 0 & $0 \%$ \\
\hline 3 & Cukup Harum & 34 & $28 \%$ \\
\hline 4 & Harum & 75 & $63 \%$ \\
\hline 5 & Sangat Harum & 11 & $9 \%$ \\
\hline & Total & 120 & $100 \%$ \\
\hline
\end{tabular}

Sumber: Data Kuesioner yang diolah

Berdasarkan tabel 7 diatas maka hasil penilaian responden terhadap aroma churros sari buah strawberry sebanyak 34 responden menyatakan cukup harum, sebanyak 75 responden menyatakan harum, dan sebanyak 11 responden menyatakan sangat harum.

4. Warna merupakan indikator penilaian terhadap churros sari buah strawberry yang menggunakan indera penglihatan dalam hal ini adalah mata. Adapun penilaian responden terhadap warna churros sebagaimana terlihat pada tabel berikut ini.

Tabel 8. Warna Churros

Sari Buah Strawberry

\begin{tabular}{|c|l|c|c|}
\hline No & Kriteria Penilaian & Jumlah & Persen \\
\hline 1 & $\begin{array}{l}\text { Sangat Tidak } \\
\text { Menarik }\end{array}$ & 0 & $0 \%$ \\
\hline 2 & Tidak Menarik & 4 & $3 \%$ \\
\hline 3 & Cukup Menarik & 44 & $34 \%$ \\
\hline 4 & Menarik & 55 & $46 \%$ \\
\hline 5 & Sangat Menarik & 17 & $14 \%$ \\
\hline & Total & 120 & $100 \%$ \\
\hline
\end{tabular}

Sumber: Data Kuesioner yang diolah.

Berdasarkan tabel 8, maka hasil penilaian responden terhadap aroma churros sari buah strawberry sebanyak 4 responden menyatakan tidak menarik, sebanyak 44 responden menyatakan cukup menarik, sebanyak 55 responden menyatakan menarik, dan sebanyak 17 responden menyatakan sangat menarik.

5. Rasa adalah indikator penilaian terhadap churros sari buah strawberry yang menggunakan indera pengecap dalam hal ini adalah mulut dan lidah. Adapun penilaian responden terhadap rasa churros sebagaimana terlihat pada tabel dibawah ini.

Tabel 9. Rasa Churros

Sari Buah Strawberry

\begin{tabular}{|c|l|c|c|}
\hline No & Kriteria Penilaian & Jumlah & Persen \\
\hline 1 & Sangat Tidak Enak & 0 & $0 \%$ \\
\hline 2 & Tidak Enak & 0 & $0 \%$ \\
\hline 3 & Cukup Enak & 31 & $26 \%$ \\
\hline 4 & Enak & 62 & $52 \%$ \\
\hline 5 & Sangat Enak & 27 & $22 \%$ \\
\hline & Total & 120 & $100 \%$ \\
\hline
\end{tabular}

Sumber: Data Kuesioner yang diolah.

Berdasarkan tabel 9 diatas maka hasil penilaian responden terhadap rasa churros sari buah strawberry sebanyak 31 responden menyatakan cukup enak, sebanyak 62 responden menyatakan enak, dan sebanyak 27 responden menyatakan sangat enak. 


\section{Hasil rata-rata Uji Organoleptik pembuatan Churros dengan Sari Buah Strawberry}

Prinsipnya hasil jadi suatu produk yang dapat dimakan dan dapat dilihat dari produk itu sendiri. Sedangkan untuk produk churros ini, jika total nilai rata-rata dari semua sampel memiliki kriteria penilaian tinggi atau besar, maka dapat dikatakan bahwa kualitas produk churros tersebut sangat baik. Begitu juga jika sebaliknya total nilai ratarata dari semua sampel memiliki kriteria penilaian rendah atau kecil, maka dapat dikatakan bahwa kualitas produk churros tersebut tidak baik.

Berdasarkan hasil olah data dapat dilihat hasil rata-rata dari penampilan, tekstur, aroma, warna, dan rasa pembutan churros dengan sari buah strawberry pada diagram berikut ini.

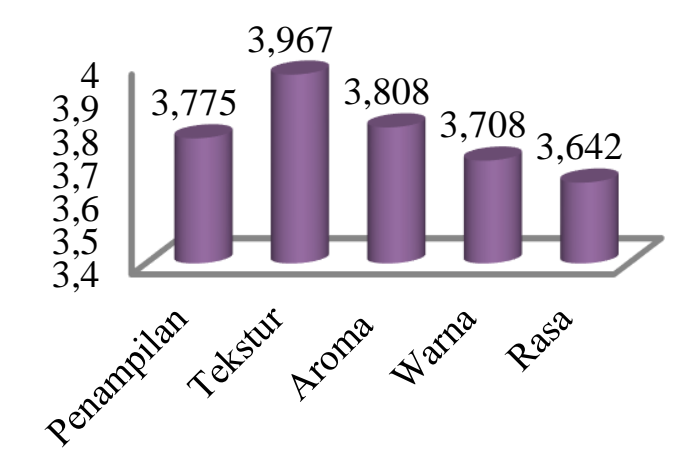

- Rata-rata Hasil Uji Organoleptik

Diagram 1. Rata-rata Hasil Uji Organoleptik Churros Sari Buah Strawberry Sumber: Data Kuesioner yang diolah.

Berdasarkan diagram 1 diatas hasil uji organoleptik churros dengan sari buah strawberry dapat dijelaskan bahwa penampilan churros dengan sari buah strawberry hasilnya rata-rata 3.775, selanjutnya untuk tekstur dengan sari buah strawberry hasilnya rata-rata 3.967, untuk aroma churros dengan sari buah strawberry hasilnya rata-rata 3.808, kemudian warna churros dengan sari buah strawberry hasilnya rata-rata 3.708, dan rasa churros dengan sari buah strawberry hasilnya rata-rata 3.642.

\section{KESIMPULAN DAN SARAN Simpulan}

Hasil olah data dan pembahasan pada pengaruh pengaruh penggunaan sari buah strawberry terhadap penampilan, tektur, aroma, warna dan rasa sebagai pengganti air mineral dalam pembuatan Churros, maka dapat disimpulkan bahwa:

1. Penggunaan sari buah strawberry terhadap penampilan dalam pembuatan churros sebanyak $20 \%$ atau baik, penggunaan sari buah strawberry terhadap tekstur dalam pembuatan churros sebanyak $21 \%$ atau lembut, penggunaan sari buah strawberry terhadap aroma dalam pembuatan churros sebanyak $20 \%$ atau harum, penggunaan sari buah strawberry terhadap warna dalam pembuatan churros sebanyak 20\% atau menarik, penggunaan sari buah strawberry terhadap rasa dalam pembuatan churros sebanyak 19\% atau cukup enak.

2. Bahwa dalam pembuatan churros dengan sari buah strawberry, ternyata terdapat pengaruh terhadap rasa churros.

\section{Saran}

Saran-saran yang dapat peneliti sampaikan berdasarkan hasil olah data dan pembahasan yang telah dilakukan melalui uji organoleptik dan penyebaran kuesioner, maka perlu adanya masukan dan saran sebagai berikut:

1. Perlu adanya penelitian yang lebih mendalam terhadap proses pembuatan churros dengan sari buah strawberry, khususnya untuk penilaian rasa.

2. Perlu dilakukan proses tindak lanjut terhadap pembuatan churros dengan varian yang berbeda.

3. Sebaiknya pula perlu ada uji ulang terhadap pembuatan churros dengan sari buah strawberry sehingga bisa menjadi alternatif varian churros.

\section{Daftar Pustaka}

Adrian, Felix dan Setiawan Dalimartha, 2011. Khasiat Buah dan Sayur. Bogor: Penebar Swadaya

Agus Mertayasa, I Gede. 2012. Food and Beverage Service Operational. Yogyakarta: Andi

Arikunto, Suharsimi. 2003. Prosedur Penelitian, Suatu Praktek. Jakarta: Bina Aksara 
Assauri, Sofjan. 2008. Manajemen Produksi dan Operasi. Jakarta: Fakultas Ekonomi Universitas Indonesia

Bartono. 2005. Food Product Management. Yogyakarta: Andi

Cahya, Putriana. 2019. 11 Ide Unik Olahan Churros yang Kreatif, Bikin Gak Bisa Setop Makan. https://www.idntimes.com/food/diningguide/putriana-cahya/11-ide-unik-olahanchurro-yang-kreatif-bikin-gak-bisa-setopmakan/11 (diakses pada 28 Juli 2020)

Faridah, Anni, dkk. 2008. Patiserri jilid I. Jakarta: Direktorat Pembinaan Sekolah Menengah Kejuruan

https://id.wikipedia.org/wiki/Air_mineral\#: :text $=$ Air\%20mineral\%20adalah\%20air\%20yang ,air\%20yang\%20berada\%20di\%20alam., (diakses pada tanggal 17 Juni 2020)

https://www.encyclopedia.com/education/ dictionaries-thesauruses-pictures-and-pressreleases/churros, (diakses tanggal 17 Juni 2020)

https://media.neliti.com/media/publications/8233 2-ID-analisis-pengaruh-kualitas-makanandan-p.pdf (diakses tanggal 14 Juli 2020) https://pergikuliner.com/blog/tahukah-kamuperbedaan-pastry-dan-bakery\#: :text= Pastry\%20merupakan\%20salah\%20satu\%20 pengetahuan,kue\%20kontinental\%20maupu $\mathrm{n} \% 20 \mathrm{kue} \% 20$ oriental.\&text $=$ Sementara $\% 20$ bakery\%20merupakan\%20bagian\%20dari,cr oissant \%20dan\%20produk\%2Dproduk\%201 ain. (diakses tanggal 7 Juni 2020)

https://www.encyclopedia.com/education/ dictionaries-thesauruses-pictures-and-pressreleases/churros, (diakses tanggal 17 Juni 2020)

https://www.tokomesin.com/peluang-usahachurros-dan-analisa-usahanya.html\#: : text=Makanan\%20churros\%20ini\%20merup akan\%20makanan,bentuk\%20lonjong\%20de ngan\%20permukaan\%20bersegi.\&text=Chu rros\%20ini\%20merupakan\%20salah\%20sat u,ini\%20terbuat $\% 20$ dari $\% 20$ tepung $\% 20$ teri gu. (diakses tanggal 7 Juni 2020)

Kholmi, Masiyal. 2003. Akuntansi Biaya. Edisi Empat, Yogyakarta: BPFE
Moleong, Lexy J. 2011. Metodologi Penelitian Kualitatif Edisi Revisi. Bandung: PT. Remaja Rosdakarya

Mulyadi, 2005. Akuntansi Biaya. Edisi Kelima. Yogyakarta: Universitas Gajah Mada

Satalkar. 2009. Metabolic Fruit Acidosis, Necrodizing Enterocolitis. Edisi dua. New York.

Subagyo, Adjab. 2007. Manajemen Pengolahan Kue \& Roti. Yogyakarta: Graha Ilmu

Sudewi dan Patriasih R. 2005. Pengolahan Kue dan Roti. Bandung.

Sugiyono. 2013. Metode Penelitian Pendidikan Pendekatan Kuantitatif, Kualitatif dan R\&D. Bandung: Alfabeta

West B.B, Wood L, Harger VP. 2006.Food Service in Intituitions. New York: John Willey and Sons, Inc

Widiatmoko, Hani. 2016. Sehat Tanpa Obat dengan Si Merah Stroberi. Edisi Pertama. Yogyakarta: Andi

Waysima dan Adawiyah, D.R. 2010. Evaluasi Sensori Produk Pangan. Edisi I. Bogor: Teknologi Pertanian IPB 